DOI: 10.2478/pcssr-2018-0006

\title{
Hegelian Phenomenology of Spirit and Boxing Fight
}

Authors' contribution:

A) conception and design of the study

B) acquisition of data

C) analysis and interpretation of data

D) manuscript preparation

E) obtaining funding

\section{Jerzy Kosiewicz}

Josef Pitsudski University of Physical Education, Poland, Warsaw

KEYWORDS

In the presented text the author points out to anthropological as well as axiological foundations of the boxing fight from the viewpoint of Hegel's philosophy. In the genial idealist's views it is possible to perceive the appreciation of the body, which constitutes a necessary basis for the man's physical activity, for his work oriented towards the self-transformation and the transformation of the external world, as well as for rivalry and the hand-to-hand fight. While focusing our attention on the issue of rivalry and on the situation of the fight - and regarding it from the viewpoint of the master - slave theory (included in the phenomenology of spirit), it is possible to proclaim that even a conventionalised boxing fight - that is, restricted by cultural and sports rules of the game - has features of the fight to the death between two Hegelian forms of selfknowledge striving for self-affirmation and self-realisation. In the boxing fight, similarly as in the above mentioned Hegelian theory, a problem of work and of the development of the human individual (that is, of the subject, self-knowledge, the participant of the fight) appears. There appears also a prospect of death as a possible end of merciless rivalry. The fight revalues the human way in an important way, whereas the prospect for death, the awareness of its proximity, the feeling that its close and possible, saturates the life with additional values. It places the boxer, just like every subject fighting in a similar or a different way, on the path towards absolute abstraction - that is, it brings him closer to his self-fulfilment in the Absolute, to the absolute synthesis.

The Hegelian viewpoint enables also to appreciate the boxing fight as a manifestation of low culture (being in contrast with high culture), to turn attention to the relations which - according to Hegel - take place between the Absolute and the man, as well as to show which place is occupied by the subject both in the process of the Absolute's self-realisation and in the German thinker's philosophical system. Independently of the dialectical, simultaneously pessimistic and optimistic overtone of considerations connected with the very boxing fight (regarding destruction and spiritualisation on a higher level), it is possible to perceive farreaching appreciation of the human individual in Hegel's philosophy since the Absolute cannot make its own self-affirmation without the individual, without the human body, without the fight aimed at the destruction of the enemy and without the subjective consciousness and the collective consciousness which appear thanks to this fight. Thus, it is justified to suppose that the foundation of the whole Hegel's philosophy is constituted by anthropology and that in the framework of this anthropology a special role is played by the fight and by work, which changes the subject and his(her) environment. Admittedly Hegel does not emphasise it explicitly, nevertheless his views (with their centre, which, according to Hegel himself and his interpreters, is constituted by the Absolute) have, as a matter of fact, an anthropocentric character and the main source of the subject's development is the struggle which, irrespectively of its result, always primarily leads to the destruction or even to the death of one of the sides, just like in the boxing fight. However, it is also a germ of the positive re-orientation of the subject, the beginning and a continuation of that what the phenomenology of the spirit describes as a movement towards absolute abstraction.

Absolute's self-fulfilment, boxing, praise of corporeality, absolute abstraction, phenomenology of spirit

\section{Anthropology as a foundation of the metaphysical sense of the Absolute's self-fulfilment}

The Hegelian concept of man is characterised by the supremacy of the spirit over the body. It means, to put concisely, that the abovementioned spirit is the whole of our accessible and inaccessible reality. It constitutes and fills the whole world; the cosmos and everything beyond the cosmos, beyond nature. It is, as a 
whole, an endless life, a process of self-development where the development of man's consciousness both in its ontogenetic and phylogenetic sense- is a necessary stage in his self-creation and self-affirmation.

The appearance and development of human and then of collective - consciousness is conditioned by nature as such, and especially by animate nature, by the human body. The Absolute, in spite of the fact that it constitutes a complete and perfect entirety, feels the need for self-affirmation. It is constituted by the realisation of its own possibilities and by its self-elucidation in the human spirit in the form of the self-thinking and selfcognition thought.

Human consciousness, created in this way, is the spirit's return to itself. It is simultaneously the end of its self-affirming subjective/objective peregrination through various forms of material and ideal (abstract, mental) beings, which are created by it, as well as by the social history in the form of collective consciousness, culture and civilisation.

This is the place where philosophical reason, the Absolute's all-embracing panlogism which treats the history of the universe as its self-development and self-cognition, manifests itself. The Absolute perceives itself in nature and in the human bodily/spiritual composition, where its self-affirmation as supra-cosmic (transgressing cosmos) and cosmic (placed in nature) reason on the path to self-fulfilling synthetic finitude objectifies itself. It leads to the conclusion that it is an indispensable condition, that the foundations of the Hegelian metaphysical sense are constituted by anthropology.

\section{Anthropogenesis and otherness, mediation and struggle}

While regarding the boxing fight from the viewpoint of the Hegelian concept of anthropogenesis, otherness and mediation it is justifiable to proclaim that at the very beginning of his existence (that is, in the period of training, before the beginning of his so-called boxing career) the boxer as self-knowledge, that is, as a subject, a human individual, a human being is a being possessing only the knowledge of himself. He is not all owe $\mathrm{d}$ to fight and in connection with this; he cannot compare his abilities and possibilities, his fitness and technical/tactical training with others, to his rivals. His knowledge is focused on himself. Admittedly, he is aware that the confrontation is unavoidable in the future, but be does yet not know his future rival, which means that he does not perceive otherness. Taking into account what Hegel wrote when he presented the conflict of mutually opposing forms of self- knowledge, he is a simple being for himself, he is equal to himself he is a direct and particular being.

At the beginning the man boxer's self-knowledge is restricted to the discovery of his own mental and physical qualities. This is precisely the reason why be is a direct being since he defines himself without referring to other beings, to particular future rivals who are not known yet. He does not mediate itself in them since he does not know them and do es not perceive them. In this sense, the boxer is one for himself that is, he is a particular being. Everything which is "other" than him, that is, other specific rivals is unimportant to him. If there is not a fighting situation, if no confrontation is going to take place, the very training is of no importance for the boxer, for his development as a subject created for the fight.

The real development and affirmation of qualities and qualifications of the boxer as a being (destined by himself to fight), both in its mental and corporeal sense, begins from mediation, from the abolition of directness, which leads also to the abolition of particularity. It takes place when self-knowledge - that is the boxer - discovers the existence of otherness; of the adversary it will be necessary to measure his own strength against. He defines himself, he affirms his identity by perceiving the qualities of another being; that is, another boxer. He measures his own abilities against this other being. He diagnoses himself and his opponent.

The attitude towards the rival (and future rivals) he is going to encounter in a sporting conflict - that is, in the situation of the fight, which is unavoidable for both of them, is going to determine his future development. It refers also to the necessity of such a change of both mental and physical individual qualities which enable the fight to be taken up. The appearance of a relational situation, the reference to otherness as to a future rival; the stimulation of motivations and of the strength of will to overcome the fear of the outcome of the fight and physical preparation for the tight, which can considerably limit its negative results, are significant in this respect. The boxing fight which is an artificially created and conventionalised conflict between two opposing forms of self-knowledge (with real- and often tragic consequences) unleashes a creative attitude 
towards the existing environment and towards himself, and it constitutes a manifestation of a self-creative and self-affirmative activity of the boxer.

The indicated type of negation, that is, in this case, defining the adversary as otherness, at the outset leads to defining one's own identity (that is, boxing abilities) and then to a conflict (that is a fight), which can result in the annihilation of the rival. At the initial stage, that is, before the match, in the preparatory period, we first of all have to deal with the vital and sensual existence "drowned in the being of life" and guided by biological drivers. The knowledge of the situation of the fight, that is full knowledge of the fight, is formed and shaped being based solely on the direct experience, which, according to Hegel, cannot be replaced by anything.

It is the fight, maintains Hegel, which the boxer (self-knowledge) has to take up since his own certainty of existence that is the affirmation of the sensibility of the choice of a given form of existence, must be raised by him to the status of truth, both in the other's self-knowledge and in himself. And it is precisely the exposing of one's own life to danger which enables freedom to be achieved. This freedom is connected with voluntarily risking one's own life. The competitor who does not expose his own life to danger does not achieve the truth of being recognised as self-sufficient, fully experienced, mediated in the fight and in the adversary boxer's selfknowledge.

Hegel assumed that the struggle plays the most important role $m$ anthropogenesis since it initiates the whole evolutionary process of anthropological development, that in spite of the fact that it is based, first of all on bodily skills and fitness - it provides the feeling of freedom from natural determinants, from vital and biological qualities. He writes that "Anthropogenic activity assumes the form of a prestigious fight to be recognised by the adversary. Human individuality is abstraction from animal directness and consists in a pure negation of one's own objective way of being, of showing that I am not connected with life" (Hegel, 1963, p. 211).

The awareness of freedom and human self-respect is according to Wiesław Gromczyński, the creation of the situation in which biological values become sub-ordinated to ideal values. Humanisation of existence assumes deliberately taking the risk of losing one's own life. Man, in order to confirm his own human selfrespect, is ready to sacrifice what the instinct of each animate being commands to be recognised as the most important thing - the biological existence (Gromczyński, 1969, pp. 125-231).

\section{The preservation of the existence of the two "extreme segments" as a condition for the continuation of the movement of absolute abstraction}

Against common sense and that sense of the fight which has been primarily implicitly assumed, it appears that the condition for the further development of self-knowledge is constituted neither by victory nor the complete destruction of the adversary his death, but by one's own loss and the recognition of the adversary's superiority and supremacy, which, to a greater or lesser degree, means the enthronement of the adversary; that is, of the other's self- knowledge. It refers to the enthronement in relation to otherness, the situation in a team, a club or in competitions of a definite rank.

The very fight, as a fight taking into account the possibility of losing one's own life, is important because it leads to the maximal mental and bodily effort facilitating further development, to the affirmation of vital forces. Prom the viewpoint of common sense, it seems that winning the fight is the most important thing since it brings a full affirmation of the success and of the superiority of the victorious selfknowledge. However, the second self-knowledge is that the contestant's death leads to the abolition of mediation; that is to the abolition of the second extreme segment it is mediated in. It abolishes a direct testimony of its competitive influence. A relational connection is broken. The subject is mutilated since it is deprived of the possibility of adopting one' s own attitude towards the adversary. The whole rich experience becomes deprived of its point of reference. What is left is emptiness, which is in a sense similar to that emptiness which appears after the departure of a person we were closely psychophysically connected with.

Admittedly, the certainty that both sides (both extreme segments) have exposed their lives to danger and that they hold their own life and that of the other in contempt appears thanks to death. However, this is not the 
case for those who emerge victorious from a fight, since the winner makes it impossible for himself to achieve the aim of the fight, which is - at this stage of the movement of absolute abstraction the achievement of recognition; that is, of the certainty of himself. The other person's death abolishes the possibility of defining oneself on the basis of otherness. Because of this the victorious self-knowledge becomes again a simple, direct, particular being for itself.

Both rivals, the winning as well as the defeated one, while striving for the realisation of absolute abstraction, have, according to Hegel, to preserve the existence of the two "extreme segments" desiring to be something for themselves. Each of the adversaries taking part in the fight strives to keep up mediation for different reasons important to them. The winning self-knowledge contains the striving for the annihilation of the defeated self-knowledge, since it does not want the return to primary directness based on subjective selfconfidence, which would mean the appearance of the above mentioned, relational, reminiscent, psychological emptiness causing the regress to the starting point.

On the other hand, the defeated adversary reaches the conviction that although the completion of the fight by death could give him, in the last experience of his life, the sense the he has become absolute negation and a pure being in itself, life is nevertheless something more important for him than the state of pure selfknowledge achieved, updated and culminated in the act of death. Seeing that a continuation of the fight and further resistance exposes his life to the risk of death, he retreats. He resigns from the fight, surrendering himself to the winner. He agrees, as is remarked by Gromczyński, to recognise the winner's superiority. The existence of the defeated affirms the winner's supremacy. It affirms his status with all his sports-boxing activity. Without the defeated, who mediates the winner's self-knowledge, there is no supremacy.

The winner owes the certainty of his identity to the recognition by the defeated; that is, to a mediated relation towards his own existence. However, this recognition is not voluntary; the adversary, who, surrendering to the instinct for self-preservation, preferred to choose defeat over possible death, was forced to recognise the winner (Ibid.).

That decision becomes the beginning of the second stage of the movement of absolute abstraction. The loss of superiority, achieved at the cost of the resignation from the victory or the possible loss of life, is a necessary stage leading, according to Hegel, to the achievement of complete freedom. It has also been necessary to strain one's vital forces, to develop physical qualities and fitness for the needs of the fight. It will be continued in order to ensure further personal survival and to overcome the inferiority complex towards the self- knowledge which has succeeded.

\section{The relation of inequality as a herald of the winner's tragedy and of the emancipation from the defeat}

The relation of inequality appears between former adversaries. On the one side, there is the winner; on the other, there is self-knowledge, which has been defeated. Both forms of self- knowledge are necessary for each other. Hegel says that "self- knowledge achieves its fulfilment only as another form of self-knowledge" (Hegel, 1963, p. 211).

The winner confirms his self-respect by taking delight in the victory, he benefits from this situation. It is the moment when his situation begins to take on a tragic character: firstly, because of the fact that the adversary's surrender has resulted from the fear of unknown, unpredictable consequences; secondly, because his superiority is recognised by a being that as a result of the fight, has a lower individual and social status. Complete, true satisfaction for the winner could be provided only by the recognition of his value by persons who have a similar sense of self-respect (Hegel, 1963, pp. 223-224). The tragedy is also based on the fact that the winner is a winner only because there is a defeated; that he must, for that reason, accept the source of his own low self- esteem: a necessary mediation in a being who is weaker than himself since there is no other choice.

The upholding of this situation brings die winner, paradoxically and against his own conviction, disadvantageous consequences; that is, the loss of mediation and the regress to the primary level, which means the level of self-knowledge of a particular and direct character.

On the other hand, the situation of the defeated is, according to Hegel, quite different, since he finds the sense of his existence just in that situation; that is, in work connected with improving his own abilities, 
connected with the realisation of the sense which has been initiated by him when the second stage of the movement of absolute abstraction has begun.

Hegel seems to warn by pointing to the fact that the achievement of the victory, of the sporting success, may conceal the danger of stagnation; that is; the conviction that after the achievement of the championship there is no longer a need to prove one 's own sporting superiority; that it has been achieved once and for all, that its result is final and unchangeable. On the other hand, the defeat according to Hegel forces the defeated self-knowledge to optimise its activity towards itself and towards everything which is going to facilitate its development and the maximisation of the boxing craft. That is the defeat positive disintegration, as it would be called, after Hegel, by Kazimierz Dąbrowski, which facilitates the integration on another, higher level work that is, the boxer's work on himself and his environment is the main factor with which he transforms and shapes himself; it has a creative character. It enables him to gain and deepen his human dignity. Thanks to it, it is only he who finally gains superiority over the winner; he becomes better in the field of sporting activity. He becomes independent of the winner/defeated relation which has undermined his competitive qualities. He rises to the level of true existence. On the other hand, the winner, lost in the well-being of success, stagnates in the state of the non-creative and idle existence. He loses his superiority over the defeated.

\section{An anthropo-creative sense of human work}

Hegel points to an anthropo-creative sense of the human activity, overcoming individual psychophysical and relational decomposition of the subject. The defeat induces destructuralisation, which provides encouragement after his failure to change the existing sanatio. It has a positive implication, which is why it can be called - in conformity with the Hegelian dialectical principle - positive disintegration. It is because of the fact that it is negation of negation and that its consequence is the synthesis; that is, defeating the winner, which means the achievement of maturity of self-realisation and self- affirmation on a level which is higher in relation to the thesis and the antithesis.

The sense of the Hegelian concept of work, constituting the consequence of the defeat and the basis for improving the art of boxing by oneself, consists, according to Panasiuk, of the fact that it is just that special act which, as a matter of fact, enables the origin of the subject in its proper sense, which unites the theoretical reason and the practical reason, the cognitive element and the volitional element in the subject which have been separated in the hitherto philosophical tradition. Here the subject becomes the unity of the spirit and the body, cognition and the activity. Only through the act of work does the subject overcome its separation from the thing as a "being in itself" its alienation from what induces negative reminiscences and associations. In the act of work it saturates itself and the social environment with the results of its effort, with its qualities. Apart from that, work as a deliberate and purposeful activity creates the foundation for the world of the spirit as a specific reality where the subject will manifest its existence from now on (Panasiuk, 1979, p. 43).

\section{The Body as a Temple of the Spirit - a Hegelian Praise of Corporeality}

Both the fight and work connected with preparing for it develop the whole human being in every respect. Its indispensable condition is the human body, physical abilities and skills. These are all correlated with the consciousness which develops in the course of realising successive tasks. That consciousness has been placed in self-knowledge; that is in man. In the subject's biological sphere, just in order to enable the Absolute to continue successive stages of the "movement of absolute abstraction" and to bring them to a synthetic crowning end. If you warn to make your own peregrination through subjective and collective consciousness, the human body and the development and improvement of its qualities are necessary. The body acquires in a way, similarly to the views of Paul of Tarsus, the status of the temple of spirit a special place with a sacral overtone, where the Absolute must dwell and develop various forms of its activity on its way to the full and final selfrealisation sod self-affirmation. It is treated both in an autotelic and instrumental, a subjective and an objective way; it is simultaneously the end in itself and a necessary stage of the movement towards absolute abstraction. In that sense taking into account that Hegel praises an extreme form of idealistic philosophy - it is great praise for human corporeality. 


\section{Creative Activity as a Condition for Freedom of the Infinite Spirit}

Thanks to the fight and work, thanks to physical, mental and relation activity "a new form of selfknowledge comes in to being; consciousness which thinks that it is free self-knowledge" (Hegel, 1963, p. 230). The subject, as free self-knowledge as rational consciousness, paying attention to itself as to a finite self, perceives itself as an objective expression of the infinite spirit with which it unites itself. Thanks to the fight and work, the Absolute's thought, realising itself in corporeality, in the psyche, in the external being, abstracts itself completely and achieves full freedom, which has been designed in a panlogical plan.

This viewpoint is confirmed by Frederick Copleston 1995, pp.176-187; in his interpretation of Hegel), who expresses the opinion that the finite subject clearly realises that its deepest self is only a moment in the life of the infinite and universal spirit, a moment in the absolute thought. The knowledge of one's own situation, of one's own place in the process of the Absolutes self-affirmation enables the man to look at the entirety which he sees from a rational, that is, an objective distance; to perceive it as a form of his own objectification. It constitutes a preliminary condition for his own life as an actually ousting spirit. It does not mean, of course, that the definite subject taken precisely as such looks at itself and on the environment it influences as at its own product. It means rather that the finite subject, aware that it is something more, that it is a moment in the deepest life of the absolute spirit, takes up the fight and work, and. as its effect, the next fight as a necessary stage in the spirit's movement in the process of self-realisation. It and its activity are the necessary conditions for approximation towards complete self-affirmation - mature, fulI and absolute knowledge.

The boxer, the subject who has taken up a fight, is, as a matter of fact, from the viewpoint of the Hegelian concept, the self-realising Absolute. The Absolute creates all his qualities of a biological/mental/relational character. It stimulates the need for a confrontation, a conflict in the form of a fight connected with the danger of losing one's own life. It leads to a path towards absolute abstraction. It certifies its first stage by arousing fear in the boxer. It leads to self-destruction assuming the shape of positive disintegration. This is the beginning of the second stage of the movement towards absolute abstraction; that is, towards the Absolute's full selfidentification on the basis of bodily, volitional and cognitive experiences which arc brought about, controlled, developed and completed by it. It is connected with stimulating the need for the next confrontation and victory over the winner in the defeated, which determines the sub- sequent development of the boxer as selfknowledge; that is, the self-knowledge which is the Absolute's self-realising freedom. In that sense, taking into account its role in a given epistemological, rational and panlogical process, it is self-knowledge which is free because of its entanglement in well-understood necessity.

Necessity and simultaneously freedom, as well as the epistemological process, possess, as a matter of fact, an ontological status (homogenous but differentiated on the way to absolute abstraction) which is primarily and finally of an absolute character. It is because they are nothing else but the Absolute which selfrealises in the boxer, achieving (obviously) the absolute knowledge. Thus, anyone who fights, the boxer in this case, approaches himself as closely as it is possible for the human being to approach absolute cognition. He realises in this respect the formula of a cognitive ideal included in neo-platonic definitions referring to Aristotle as well as to pre- and post - Aristotelian interpretations of philosophy. Approaching oneself to the epistemological ideal is, as a matter of fact, the movement towards absolute abstraction; thus, it is a peregrination initiated by the Absolute and realised by the Absolute in self-knowledge; that is, in the fighting man, in the boxer. Thus the Absolute brings itself closer to itself. This means that the boxer, while approaching the Divine, is in fact the Absolute realising itself (Copleston, 1995, pp. 189-190).

This paper was prepared within the framework of the statutory research Ds. - 277registered by the Ministry of Science and Higher Education.

\section{REFERENCES}

Copleston, F. (1995). Historia filozofii [History of Philosophy]. Warszawa: PAX, 176-187.

Hegel, G .w.F. (1963). Fenomenologia ducha [Phenomenology of Spirit] vol. 1. Warszawa: PWN. 
Gromczyński, W. (1969). Heglowska teoria Pana i Niewolnika i jej wpływ na Sartre'a [Hegelian Master-Slave Theory and Its Influence on Sartre]. In Człowiek, świat rzeczy, Bóg w filozofii Sarte'a. Warszawa: PWN.

Panasiuk, R (1979). Koncepcja podmiotu poznania w Hegla "Fenomenologii ducha" [The Concept of the Subject of Cognition in Hegel "Phenomenology of Spirit"]. In Dziedzictwo heglowskie a marksizm. Warszawa: KiW.

\section{AUTHOR'S ADDRESS: $\quad$ Jerzy Kosiewicz}

Josef Pilsudski University of Physical Education in Warsaw

Department of Philosophy and Sociology

34 Marymoncka Street

00-968 Warsaw

E-mail: jerzy.kosiewicz@awf.edu.pl

Received: 1 December 2017; Accepted: 15 Febrauary 2018 